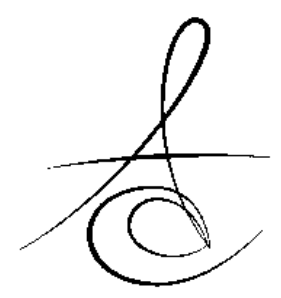

\section{YENİ IŞIKSIZ SERTLEŞEN ÜNİVERSAL BONDUN DİĞER ÜNİVERSAL BONDLARLA BAĞLANMA ÖZELLİKLERİ VE KALİTELERİNİN MAKASLAMA VE FTIR YÖNTEMLERIYYLE KARŞILAŞTIRILMASI}

\section{COMPARISON OF BONDING PROPERTIES AND QUALITY OF A NEW NON-LIGHT POLYMERIZING UNIVERSAL BOND WITH OTHER ÜNIVERSAL BONDS BY SHEAR AND FTIR METHODS}

Prof. Dr. Mehmet YILDIZ**

Makale Kodu/Article code: 6101

Makale Gönderilme tarihi; 16.07 .2021

Kabul Tarihi: 24.08.2021

DOI : $10.17567 /$ ataunidfd.998956

Mevlüt Emre Sönmezateş: ORCID ID: 0000-0003-1077-4475

Mehmet Yıldız: ORCID ID: 0000-0002-4169-0090

\title{
Öz
}

Amaç: Konservatif diş hekimliğinde yapılan araştırmalar ve bunun sonucunda elde edilen bulgularla adezyon önem kazanmışır. Üniversal veya multi-mod adezivler, adezyon konusunda son zamanlarda üzerine düşülen materyallerdir. Bu materyaller bütün komponentleri tek bir şişede toplayarak uygulamayı basitleștirmiş̧lerdir. Bu çalışmanın amaç piyasaya yeni sürülmüş olan ışık kullanma süresini pas geçerek kendiliğinden polimerize olan üniversal bonding ajanın bağlanım kalitesini kliniklerde sıkça kullanılan diğer üniversal bonding ajanlarla makaslama bağlanma dayanımı testi ve FTIR yöntemleriyle kıyaslayarak değerlendirilmesidir.

Gereç ve Yöntem: Calıșmamızda bonding ajanların dentin bağlanma dayanımı belirlemek için makaslama bağlanma dayanımı testi, infiltrasyonlarını kıyaslamak için FTIR analiz testi yapıldı. Her test için 110 örnek kullanıldı. Bunların 10 tanesi kontrol grubu için ayrıldı. Kalan 100 tanesi self etch ve total etch asitleme modları için eşit olarak iki gruba ayrıldı. Her grup da kendi içinde $n=10$ olmak üzere 5 farklı bonding ajan uygulanmak üzere 5 gruba ayrıldı. Gruplar ayarlandıktan sonra dentin üzerinde makaslama bağlanma dayanımı ve FTIR analiz testleri yapıldı. Makaslama testi ve FIIR analiz testi sonucunda elde edilen verilerin arasındaki farklılı̆ın belirlenmesi amacıyla tek yönlü varyans analizi (One Way Anova) yapıldı. Örneklerin kendi aralarında kıyaslanması için Duncan, Kruskall-Wallis ve Mann-Whitney yöntemleri kullanıldı. FTIR ve makaslama bağlanma dayanımlarını birbirleriyle karşılaştırmak için Spearman analizi kullanıldı. Bulgular: Makaslama bağlanma dayanımı testi sonucunda farklı adezivlerin arasında anlamlı farklar bulundu $(p<0.05)$. En yüksek bağlanma dayanım ortalamaları Futura Bond Üniversal total etch modunda $(9.95 \pm 1.19 \mathrm{MPa})$ olurken en düsük bağlanma dayanım ortalamaları ise Tokuyama Üniversal Bond self etch modunda(5.45 $\pm 0.34 \mathrm{MPa})$ çıkmıştır. Futura Bond Üniversal, Single Bond Üniversal ve All Bond Üniversal bonding ajanlarının total etch modu anlamlı olarak diğer örneklerden daha yüksek bağlanma dayanım değerleri vermiş̧tir $(p<0.05)$. FTIR analizine göre en fazla dentine infiltre olan bonding ajanı Tokuyama Üniversal Bond total etch modu örnekleri bulunmuştur. All Bond Üniversal self etch modu örnekleri ise en az infiltrasyon gösteren grup olmuştur.

Sonuçlar: Ișıkla polimerize olan üniversal bonding ajanlar kimyasal polimerize olan bonding ajandan daha iyi bağlanma dayanımı değerleri göstermiştir. Işıksız polimerize olan bonding ajan ışıkla polimerize olan bonding ajanlardan daha iyi dentine infiltre olmuştur. Anahtar Kelimeler: Işıkla polimerize bonding ajanlar, IşıkSız polimerize olan bonding ajanlar, FTIR, Makaslama bağlanma dayanımı

\section{ABSTRACT}

Aim: Conservative dentistry has begun to develop with the preference of dental color restorative materials compared to other restorative materials. With the continuous development of conservative dentistry, adhesive technology has become even more important. Universal or multimodal adhesives are recent innovations in adhesive dentistry. These materials simplify the application by collecting all components in a single bottle. The aim of this study is to evaluate the quality of bonding of a new bonding agent, which has been recently introduced to the market, that offers less technical precision and less application time, compared to other universal bonding agents commonly used in clinics. Materials and Methods: In our study, FTIR analysis test was used to determine the infiltrations of the bonding agents and shear bond test was used to evaluate strength of the adhesive agents while bonding to the dentin. 110 samples were used for each test. Ten of them were sorted for the control group. The remaining 100 were equally divided into two groups for self etch and total etch modes. Each group was divided into 5 groups to apply 5 different bonding agents and each group was consisted of 10 samples. After adjusting the groups, shear bond strength and FTIR analysis tests were performed on dentin. One Way ANOVA (One Way Anova) was used to determine the difference between the data obtained from the shear test and FTIR analysis test. Duncan, Kruskall-Wallis and Mann-Whitney methods were used to compare the samples in each other. Spearman analysis was used to compare FIIR and shear bond strengths.

Results: Significant differences were found between different adhesives as a result of shear bond strength test $(p<0.05)$. The highest bond strength values were in Futura Bond Universal total etch mode $(9.95 \pm 1.19 \mathrm{MPa}$ ) while the lowest bond strength values were in Tokuyama Universal Bond self etch mode $(5.45 \pm 0.34 \mathrm{MPa})$. The total etch mode of Futura Bond Universal, Single Bond Universal and All Bond Universal bonding agents was significantly higher than the other samples $(p<0.05)$. According to the FTIR analysis, the most infiltrating bonding agent Tokuyama Universal Bond total etch mode was found. All Bond Universal self-etch mode samples were the least infiltrating group.

Conclusion: The light-curing universal bonding agents showed better bond strength values than the self polymerizing bonding agent. Chemical polymerizing bonding agent has been better dentine infiltration than light-polymerizing bonding agents. Keywords: Light-cured bonding agents, Lightless-cured bonding agents, FTIR, Shear

${ }^{*}$ Karaağaç Konarlı Mah. Ortayol Cad. No:199 Arsuz/Hatay

${ }^{* *}$ Atatürk Üniversitesi Diș Hekimliği Fakültesi Restoratif Diș Tedavisi ABD Erzurum

Kaynakça Bilgisi: Sönmezateş ME, Yıldız M. Yeni ışıksız sertleşen üniversal bondun diğer üniversal bondlarla bağlanma özellikleri ve kalitelerinin makaslama ve FTIR yöntemleriyle karşıllaştırılması. Atatürk Üniv Diş Hek Fak Derg 2021; 31: 535-41.

Citation Information: Sonmezates ME, Yildiz M. Comparison of bonding properties and quality of a new non-light polymerizing universal bond with other üniversal bonds by shear and FTIR methods. J Dent Fac Atatürk Uni 2021; 31: 535-41. 


\section{GİRİş}

Diş rengi restoratif materyallerin diğer restoratif materyallere göre daha çok tercih edilmesi, konservatif diş hekimliğini gelişmeye itmiştir ${ }^{1}$. Konservatif diş hekimliğinin devamlı gelişmesiyle adezyon ve adeziv ajanlar daha da önem kazanmıştır². Üniversal veya multimod adezivler adezyon konusunda son zamanlarda yapılan yeniliklerdendir. Bu materyaller bütün komponentleri tek bir şişede toplayarak uygulamayı basitleştirmişlerdir. Üniversal adezivler hem self etch hem de etch and rinse tekniğiyle kullanılabilirler.

İn-vitro çalışmalarda termosiklus ağız içinde ısı değişimlerini taklit ettiği için sıklıkla tercih edilir. Termosiklus yaşlandırma yöntemi olarak sıkça kullanımaktadır. Bazı araştırmacılara göre diş yapısı ile restoratif materyal arasında termal genleşme katsayısındaki farklılık diş/restorasyon ara yüzeyinde yıkımlara neden olabilir 3. Termosiklus deneyinde uygulamanın sıklığı ve saklama sıcaklığı biyomateryallerin özelliklerini etkilediği bildirilmiştir ${ }^{4}$.

$\mathrm{Bu}$ çalışmada, restoratif diş hekimliğinin en önemli unsuru ve adezyonun çok değerli bir parçası olan adezivlerin mekanik ve fiziksel olarak kıyaslanması yapılacaktır. Son dönemde adeziv diş hekimliğinin önemli bir unsuru haline gelen ışıkla polimerize olan üniversal adezivler ile kendinden sertleşebilen yeni bir adezivin fiziksel olarak kıyaslanması için dentine makaslama bağlanma dayanımı ve adezivlerin dişlerin dentin dokusuna ne kadar invaze olduğu FTIR analizi yoluyla bakılacaktır.

\section{GEREÇ ve YÖNTEM}

Çalışmamız iki aşamada gerçekleştirildi. Birinci aşamada bondların makaslama bağlanım dayanımına, ikinci aşamada bondların FTIR analizleriyle örneklere ne kadar invaze olduğu incelendi. Bağlanma dayanım testinde dişler, 10 tanesi kontrol grubu 100 tanesi de deney grubu olmak üzere ikiye ayrıldı. Kontrol grubu için altın standart olarak kabul edilen 6 . nesil iki aşamalı self etch adeziv olan Clearfil Se Bond (Kuraray Japonya) bonding ajanı kullanıldı. Kontrol grubunun sayısı diğer alt grup adezivlerle eşit olması açısından 10 olarak tutuldu. Deney grubu da kendi içerisinde 50 'si total etch grubu 50'si self etch grubu olmak üzere ikiye ayrıldı. Total etch uygulaması için her grup kendi içinde 10'ar örnekli olmak üzere eşit olarak 5 gruba ayrıldı. Daha sonra sırasıyla Single Üniversal Bond (SB, 3M ESPE, ABD) G-Premio Bond (GP, GC Corp. Japonya) Futura Bond Üniversal (FBU, Voco $\mathrm{GmbH}$
Almanya), All-Bond Üniversal (ABU,Bisco Inc.ABD) ışıkla polimerize olan ajanlar kullanım talimatlarına göre uygulandı. Işıksız polimerize olan Tokuyama Üniversal Bond (UB, Tokuyama, Japonya) 5. Grup olarak uygulandı. Kompozit reçine olarak Z 250 (3M ESPEABD) kullanıldı. Daha sonra örneklere termosiklus cihazında 60 sn'lik devirlerle $5^{0-55^{0}}$ dereceler arasında 5000 termal siklus uygulanarak yaşlandırma yapıldı. Yaşlandırma işleminden sonra Instron Üniversal Test makinesinde örneklerin bağlanma dayanımına bakıldı.

İkinci aşamada örnekler makaslama kuvveti için hazırlanan örneklerdeki gibi kompozit uygulanmasına kadar olan aşamalarla hazırlanıp gruplara ayrıldı. Örnekler termal siklus döngüsüne sokulmadı. Bu analiz ile diş dentin yapısına invaze olup asidik yapılarıyla protein bağlarını bozan bond ajanların, ne kadar protein bağını bozduğu incelenerek özel aralıklarda oluşturduğu dalga boylarına bakılıp invazyon derecelerinin hesaplanması amaç edinildi. Örneklerin elmas okuyucunun üzerine tamamen düz olacak şekilde gelmesine ve adeziv uygulanan yüzeyin elmas okuyucuya denk gelmesine özellikle dikkat edildi. Ölçüm modu olarak "absorbance" seçildi. Örnekler vakum altında 4000$400 \mathrm{~cm}^{-1}$ aralığında $4 \mathrm{~cm}^{-1}$ çözünürlükte 5 dakika süreyle 350 tarama sayısıyla incelendi. Çalışmada kullanılan FTIR spektrofotometresinin optik sisteminin vakumlaması sayesinde, orta, yakın ve uzak IR/THz bölgelerinde herhangi bir su buharı ya da $\mathrm{CO}_{2}$ soğurmasının sebep olduğu zayıf spektrum özellikleri kaygısı olmaksızın ölçümler gerçekleştirildi. Elde edilen grafiklerden $1690-1740 \mathrm{~cm}^{-1}$ dalga boyu arasındaki piklerin altında kalan alan OriginLab 201932 Bit programı yardımıyla ölçüldü. Örneklerin dağıımı tablo 1'de verilmiştir.

Tablo 1. Grup dağlımları

\begin{tabular}{|c|c|}
\hline MAKASLAMA BAĞLANIM TESTİ & FTIR TESTİ \\
\hline 110 Örnek & 110 Örnek \\
\hline $\begin{array}{c}\text { Clearfil Se Bond (Kontrol Grubu) } \\
(n=10)\end{array}$ & $\begin{array}{c}\text { Clearfil Se Bond (Kontrol Grubu) } \\
(n=10)\end{array}$ \\
\hline $\begin{array}{l}\text { Self Etch }(n=50) \\
\text { - Single Bond Üniversal }(n=10) \\
\text { • G-Premio Bond }(n=10) \\
\text { - Futura Bond U }(n=10) \\
\text { - All Bond Ünniversal }(n=10) \\
\text { - Tokuyama Üniversal Bond } \\
\quad(n=10)\end{array}$ & $\begin{array}{l}\text { Self Etch }(\mathbf{n}=\mathbf{5 0}) \\
\text { - Single Bond Üniversal }(n=10) \\
\text { - G-Premio Bond }(n=10) \\
\text { - Futura Bond U }(n=10) \\
\text { - All Bond Üniversal }(n=10) \\
\text { - Tokuyama Üniversal Bond }(n=10)\end{array}$ \\
\hline $\begin{array}{l}\text { Total Etch }(n=50) \\
\text { - Single Bond Üniversal }(n=10) \\
\text { - G-Premio Bond }(n=10) \\
\text { - Futura Bond U }(n=10) \\
\text { - All Bond Üniversal }(n=10) \\
\text { - Tokuyama Üniversal Bond } \\
\text { (n=10) }\end{array}$ & $\begin{array}{l}\text { Total Etch }(\mathbf{n}=\mathbf{5 0}) \\
\text { - Single Bond Üniversal }(n=10) \\
\text { - G-Premio Bond }(n=10) \\
\text { - Futura Bond U }(n=10) \\
\text { - All Bond Üniversal }(n=10) \\
\text { - Tokuyama Üniversal Bond }(n=10)\end{array}$ \\
\hline
\end{tabular}

Makaslama testi ve FTIR incelemeleri sonucunda elde edilen verilerin arasındaki farklılı̆ın belirlenmesi amacıyla tek yönlü varyans analizi (One 
Way Anova) yapıldı. Bu analiz sonucunda örneklerin makaslama bağlanma dayanımları ve FTIR analizlerinin hem kendi içinde hem de birbirleri arasında istatistiksel olarak anlamlı sonuçlar elde edildi $(p<0.001)$. Bu farklılık Duncan, Kruskall-Wallis ve Mann-Whitney yöntemleriyle analiz edildi. İstatistiksel analizler SPSS Windows 20.0 (SPSS Inc. ABD)paket programında yapıldı. Makaslama bağlanma dayanımı ile FTIR analizlerinin birbirleriyle korelasyonu ise Spearman korelasyon testiyle yapıldı.

\section{BULGULAR}

Adeziv sistemlerin dentine bağlanma dayanma değerleri arasında istatistiksel olarak önemli farklııklar tespit edildi $(p<0.001)$. Asitleme tekniği açısından istatistiksel değerlendirme Duncan testiyle yapıldı ve Mann-Whitney $U$ testiyle de sağlandı. Total etch grubu; self etch ve kontrol grubuna göre dentine anlamlı olarak daha iyi bağlandığı tespit edildi. $(p<0.001)$. Kontrol grubu ile self etch grublarının dentine bağlanma değerleri arasında anlamlı bir fark bulunamadı. Bondların hepsinde asitleme tekniğine göre anlamlı olarak farklar bulundu.( Tablo 2)

Tablo 2. Asitleme tekniklerine örnek sayısı ve makaslama bağlanım dayanımları ortalamalarına (MPa) göre duncan analizi

\begin{tabular}{|l|l|l|}
\hline Makaslama Testi & $\mathbf{N}$ & Ortalama \\
\hline Kontrol Grubu & $\mathbf{1 0}$ & $\mathbf{6 , 1 4} \pm \mathbf{0 . 5 8 ^ { \mathbf { a } }}$ \\
\hline Total Etch & $\mathbf{5 0}$ & $\mathbf{8 , 5 2} \pm \mathbf{1 . 8 3 ^ { \mathbf { b } }}$ \\
\hline Self Etch & $\mathbf{5 0}$ & $\mathbf{6 , 9 2} \pm \mathbf{1 . 3 5 ^ { \mathbf { a } }}$ \\
\hline
\end{tabular}

Bütün bond grupları içerisinde dentine ortalama olarak en fazla bağlanma değeri Futura Bond Üniversal TE grubunda bulundu (9.95 MPa). En düşük ortalama bağlanım ise Tokuyama Üniversal SE grubu bulundu (5,45 Mpa). Bond grupları kendi içerisinde istatistiksel olarak Duncan testiyle değerlendirildiğinde, All Bond TE, Single Bond TE ve Futura Bond U TE' nin anlamlı olarak diğer gruplardan daha iyi bağlandığı bulundu. Yine bütün gruplar ele alındığında; Tokuyama Üniversal SE, All Bond Üniversal SE, Tokuyama Üniversal TE ve kontrol grubu olan Clearfil Se Bond diğer gruplardan anlamlı olarak düşük bağlanım değeri gösterdi.

Self-etch adeziv gruplarında en düşük bağlanım değerlerini Tokuyama Üniversal ve All Bond Üniversal grupları gösterdi. Bu gruplar ile diğer gruplar arasında anlamlı bir fark tespit edildi. Self-etch sistemde en yüksek bağlanımı Futura Bond Üniversal adezivinde bulumuştur. Futura Bond Üniversal ile diğer gruplar arasında anlamlı bir fark bulundu.
Total etch adeziv gruplarında en düşük bağlanım değeri Tokuyama Üniversal adezivinde bulundu. Tokuyama Üniversal adeziv ile diğer grupların arasındaki fark anlamlı bulundu. Bununla birlikte total etch grubunun en yüksek bağlanım değeri Futura Bond Üniversal grubunda bulundu. Futura Bond Üniversal ile Single Bond Üniversal ve All Bond Üniversal grupları arasında bağlanma dayanımı arasında anlamlı bir fark bulunamadı. Ancak bu gruplar diğer gruplardan dentine anlamlı olarak daha iyi bağlandığı belirlendi. Örneklerin gruplara göre ortalama makaslama dayanım değerleri $(\mathrm{MPa})$ ve $\mathrm{P}$ Değerleri tablo 3' teki gibidir.

Tablo 3. Örneklerin gruplara göre ortalama makaslama dayanım değerleri ( $\mathrm{mpa}$ ) ve $\mathrm{p}$ değerleri

\begin{tabular}{|c|c|c|c|}
\hline Bond & $\begin{array}{c}\text { Total etch }(\mathrm{n}=50) \\
\text { Mean } \pm \mathrm{sd}\end{array}$ & $\begin{array}{c}\text { Self etch } \\
(\mathrm{n}=50) \\
\text { Mean } \pm \mathrm{sd}\end{array}$ & $P$ değeri \\
\hline Tokuyama universal bond & $6,05 \pm 0,31$ & $5,45 \pm 0,34$ & $P=0.001$ \\
\hline G-premio universal bond & $7,41 \pm 0,67$ & $6,72 \pm 0,60$ & $P=0.027$ \\
\hline Futura bond universal & $9,95 \pm 1,18$ & $8,77 \pm 0,71$ & $P=0.015$ \\
\hline Snngle bond universal & $9,63 \pm 1,16$ & $7,60 \pm 0,48$ & $P<0.001$ \\
\hline All bond universal & $9,54 \pm 1,41$ & $6,02 \pm 1,02$ & $P<0.001$ \\
\hline
\end{tabular}

FTIR bulgularının asitleme yöntemine göre grupların kıyaslanmasında Duncan testi uygulandı ve sonuçlar Mann-Whitney testiyle de sağlandı. Asitleme yöntemine göre total-etch yöntemi anlamlı olarak diğer gruplardan daha düşük bulundu. Kontrol grubu ile selfetch grupları arasında anlamlı olarak bir fark bulunamadı (Tablo 4).

Tablo 4. Asitleme tekniğine göre örnek sayısı ve duncan test sonuçları

\begin{tabular}{|c|c|c|}
\hline Asitleme Tekniği & Örnek Sayısı & Ortalama \\
\hline Total Etch & 50 & $69936,88^{a}$ \\
\hline Self-Etch & 50 & $149261,18^{b}$ \\
\hline Kontrol Grubu & 10 & $200052,10^{b}$ \\
\hline
\end{tabular}

Adeziv sistemlerin kendi içlerinde asitleme sistemlerine göre kıyaslanması için Mann-Whitney U Testi uygulandı. Tokuyama Üniversal Bond ile G-Premio Bond istatistiksel olarak anlamlı farklılık gösterdi.

Gruplar arasındaki farklılıkları incelemek için veriler Duncan testine tabi tutuldu. Sonuçlara göre istatistiksel olarak anlamlı farklılıklar tespit edildi $(p<$ 0.001)

Total etch yönteminden elde edilen verilerde en düşük ortalama ışığı emme verisi Tokuyama Üniversal adezivinden elde edildi. Yine bu grupta en yüksek değer All Bond Üniversal adezivinden elde edildi. Total etch asitleme yönteminde kullanılan bondlar arasında anlamlı bir fark bulunamadı. 
Self etch asitleme yönteminden elde edilen verilerde en düşük değer Single Bond Üniversal grubunda bulundu. En yüksek değer ise All Bond Üniversal grubunda bulundu. Bondların asitleme yöntemlerine göre ortalama değerleri ve $P$ değerleri tablo 5'teki gibidir.

Tablo 5. Bondların asitleme yöntemlerine göre ortalama değerleri ve $p$ değerleri

\begin{tabular}{|c|c|c|c|}
\hline BOND & $\begin{array}{l}\begin{array}{l}\text { TOTAL } \\
(n=50)\end{array} \\
\text { Ortalama } \\
\text { SD }\end{array}$ & $\begin{array}{l}\text { SELF ETCH }(n=50) \\
\text { Ortalama } \pm \text { SD }\end{array}$ & $\begin{array}{l}P \\
\text { Değeri }\end{array}$ \\
\hline $\begin{array}{l}\text { TOKUYAMA } \\
\text { UNIVERSAL } \\
\text { BOND }\end{array}$ & $\begin{array}{c}44733,60 \pm \\
21227,73\end{array}$ & $\begin{array}{c}105449,90 \pm \\
33562,22\end{array}$ & $p=0,001$ \\
\hline $\begin{array}{l}\text { G-PREMİO } \\
\text { UNIVERSAL } \\
\text { BOND }\end{array}$ & $\begin{array}{c}64189,60 \pm \\
84271,01\end{array}$ & $\begin{array}{c}139357,30 \pm \\
102312,57\end{array}$ & $p=0,019$ \\
\hline $\begin{array}{l}\text { FUTURA BOND } \\
\text { UNIVERSAL }\end{array}$ & $\begin{array}{c}82219,90 \pm \\
81755,47\end{array}$ & $\begin{array}{c}203759,50 \pm \\
213916,35\end{array}$ & $p=0,076$ \\
\hline $\begin{array}{l}\text { SINGLE BOND } \\
\text { UNIVERSAL }\end{array}$ & $\begin{array}{l}48536,80 \pm \\
21286,95\end{array}$ & $\begin{array}{c}69003,40 \pm \\
67278,67\end{array}$ & $p=0,880$ \\
\hline $\begin{array}{l}\text { ALL BOND } \\
\text { UNIVERSAL }\end{array}$ & $\begin{array}{c}110004,50 \pm \\
70368,07\end{array}$ & $\begin{array}{c}228735,80 \pm \\
161560,623\end{array}$ & $p=0,49$ \\
\hline
\end{tabular}

FTIR çalışmasında adeziv örneklerin verdiği pikler belirtilen grafiklerde verilmiştir.
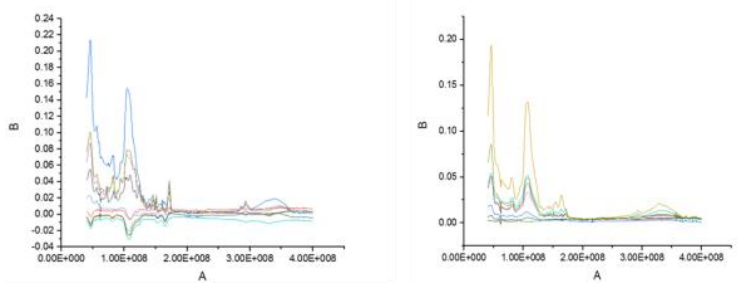

Single Bond Universal Self Etch FTIR Single Bond Universal Total Etch FIIR

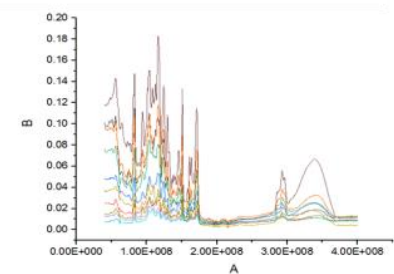

All Bond Universal Self Etch FTIR

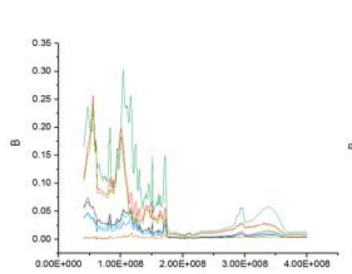

Futura Bond Universal Self-Etch FTIR Total-Etch FTIR
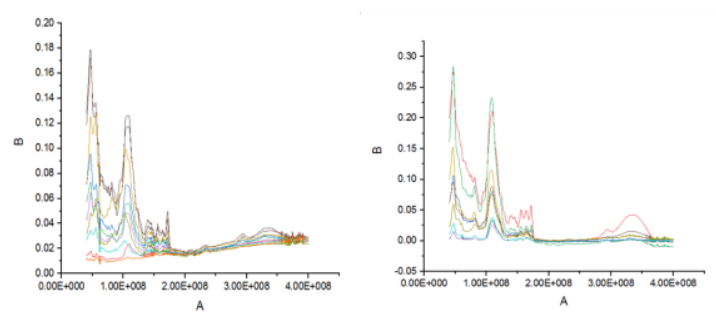

G-Premio Universal Bond Self-Etch FTIR Bond Total-Etch FTIR
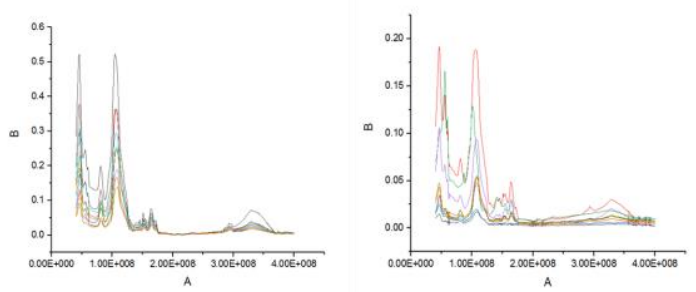

Tokuyama Universal Bond Self-Etch FTIR Tokuyama Universal Bond Total Etch FIIR

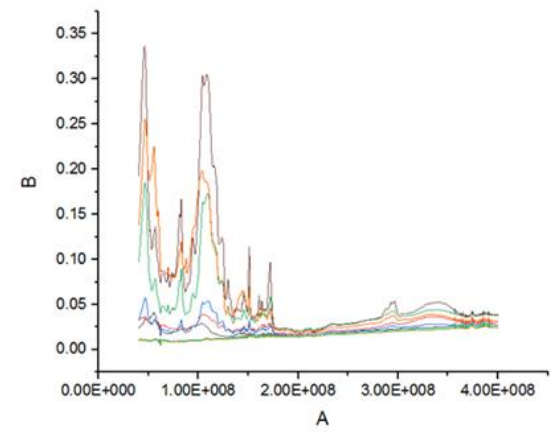

Clearfil SE Bond FTIR

Makaslama bağlanma dayanımı ve FTIR analizlerinin birbirleriyle arasında istatistiksel olarak negatif korelasyon (-0.209) ile anlamlı bir fark bulunmuştur $(p<0.05)$. Markalara göre incelendiğinde G-premio Bond, All Bond Üniversal ve Tokuyama Üniversal Bond gruplarında makaslama bağlanma dayanımı ve FTIR analizi arasında anlamlı olarak fark bulunmuştur $(p<0.05)$.

\section{TARTIŞMA}

Restoratif diş hekimliğinin en önemli öğelerinden biri olan dentin adeziv sistemler yıllardır araştırmalara konu olmaktadır. Dentin adeziv sistemlerde klinik başarının değerlendirilmesi, materyal ile diş dokusu arasındaki bağlanmanın kalitesi ve bu bağlanmanın ne kadar kalıcı olduğu ile ölçülmektedir. Bu araştırmaların temel amacı, diş dokusu ile materyal arasındaki adezyonu geliştirmektir. Bu sayede, diş yapısının korunması ve restorasyonların klinik ömürlerinin uzaması mümkün olacaktır 2, 5-8 .

Bond bağlanma dayanım testleri kalitatif ve kantitatif olmak üzere ikiye ayrılır ${ }^{9}$. Kantitatif testlerde

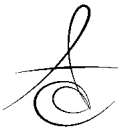


kırılma sertliğine ve kırılma enerjisine bakılır 10,11. Bulk materyallerin sertliğine ve adeziv rezinlerin diş yapısıyla arasındaki bond ajanına bu yöntemle bakılmışır 11-13. Bondların bağlanma kalitesini araştırmak için kalitatif testler tercih edilir. Kalitatif testler makaslama, germe, bükme, çekme, ayrılma, ekstrüzyon testleri ${ }^{14}$ ve dört noktadan eğme ${ }^{9}$ olarak bilinir. Kalitatif testler iyi standardize edilmiş olmalı ve yapılması kolay olmalıdır. Uygulaması en kolay olan kalitatif test "'makaslama" testidir. Çalışmamızda bondların bağlanma güçlerini kıyaslamak için İnstron üniversal test cihazıyla (Model: 3344, Instron Corp., Norwood, MA, ABD) makaslama bağlanma dayanımı kuvvetlerine bakıldı.

Fourier Dönüşümlü Kızıötesi Spektroskopisi (FTIR) inorganik ve organik komponentlerin moleküler yapısı hakkında çok önemli bilgiler sağlar. Maddelerin çok yönlü analitik incelemelerine maddelere zarar vermeden izin verir ${ }^{15-19}$. FTIR mikrostpektroskopisiyle polimerizasyon derecesi ve dentin adeziv arayüzü genişliği ve uzunluğu hesaplanabilir. ${ }^{21}$

Van Meerberk ve ark. ${ }^{22}$ ile Yoshida ve ark. ${ }^{23}$ fonksiyonel yapıştırıcı monomer olarak 10-MDP'nin diğer fonksiyonel yapıştırıcı monomerlerden daha iyi kimyasal bağ sağladığını ve su içinde daha stabil olduğunu bildirmişlerdir. Bu durum bizim çalışmamızda içeriğinde 10-MDP bulunmayan tek bonding ajan olan Tokuyama Üniversal Bond' un makaslama bağlanma dayanım değerinin diğer bonding ajanlardan daha düşük olmasını açıklamaktadır.

Makaslama bağlanma dayanımı testinde bulduğumuz değerlerin düşük olması termosiklus hızlı yaşlandırmasına bağlanılabilir. Karaman ve ark. ${ }^{24}$ yaptığı çalışmada Clearfil SE bond ile Single Bond Üniversal ve All Bond Üniversal adezivlerinin dentine makaslama bağlanma dayanımını incelemişler ve birbirleri arasında anlamlı bir fark bulamamışlardır. All Bond Üniversal adezivinin anlamlı olarak diğer adezivlerden düşük bağlanma değerleri olduğunu bildirmişlerdir. Bu çalışma bizim çalışmamızla paralellik göstermektedir.

Dentin / adeziv arayüzünün heterojen yapısına sahip olması büyük bir ilgi konusu olmuştur. FTIR analizinin dentin adeziv arayüzünün incelenmesinde iyi bir görüntüleme tekniği olduğu ispatlanmıştır. FTIR mikrospektroskopisiyle dentin adeziv arayüzünün boyunca polimerizasyon olma derecesi, kimyasal kompozisyonu ve homojenitesi, arayüzün uzunluğu ve genişliği boyunca belirlenebilir ${ }^{180}$. Çalışmamızda FTIR analizi ile adezivlerin $1690-1740 \mathrm{~cm}^{-1}$ dalga boyu arasındaki $\mathrm{C}=\mathrm{O}$ bağlarında yaptığı parmak izi piklerinin altındaki alan hesaplanarak aralarındaki fark hesaplandı. Bu aralığın alınmasının sebebi dentin ve adezivin bazı piklerinin üst üste gelmesindendir. Örneğin dentindeki mineral $\mathrm{v}_{3} \mathrm{PO}^{3-}{ }_{4}$ 'ün $1068 \mathrm{~cm}^{-1}$ dalga boyundaki pikinin $1105 \mathrm{~cm}^{-1}$ ' deki $\mathrm{SiO}_{2}{ }^{\prime}$ in pikiyle üst üste gelir ve bu da değerlendirmemizde hatalı sonuçlara neden olabilmektedir.

\section{SONUÇLAR}

Kliniklerde sıkça kullanılan ışıkla polimerize olan universal bonding ajanların makaslama bağlanım dayanımlarının piyasaya yeni sürülen kimyasal polimerize olan universal bonding ajandan daha iyi olduğu bulunmuştur. Bununla birlikte yapılan FTIR analizinde ise kimyasal polimerize olan adezivin diğer gruplardan dentin yapısında oluşturduğu piklerden dolayı daha fazla değişikliğe neden olduğunu gördük. Çalışmamızdaki başarısına rağmen total etch adeziv sistemlerde karşılaşılan klinik uygulamalardaki güçlük, uygulamanın fazla zaman gerektirmesi ve postoperatif duyarlılık gibi sorunlar nedeniyle self-etch tekniğini derin dentin çürüklerinde tavsiye ediyoruz. Yaptığımız çalışmada kimyasal yolla polimerize olan üniversal bonding ajanın mekanik özelliklerini ışıkla polimerize olan üniversal bonding ajanlardan daha düşük bulsak da kimyasal yolla polimerize olan bonding ajanı ışı̆ın ulaşamadığı 'post-core, metal braket simantasyonu, rezin bazlı dolgu materyalleriyle kök kanal dolumu" gibi tedavi protokollerinde tavsiye edebiliriz. Ancak çalışmamız klinik çalışmalarla desteklenmelidir.

\section{Finansal Destek}

Yazarl/yazarlar bu çalışma için finansal destek almadıklarını beyan etmişlerdir.

Çıkar Çatışması: Bu çalışma ile ilgili olarak yazarların ve/veya aile bireylerinin çıkar çatışması potansiyeli olabilecek bilimsel ve tıbbi komite üyeliği veya üyeleri ile iliş̧isi, danışmanlık, bilirkişilik, herhangi bir firmada çalışma durumu, hissedarlık ve benzer durumları yoktur.

\section{KAYNAKLAR}

1. Nguyen NT. Obturation of the root canal system. İn: Cohen S, Burns RC, eds. Pathways of the pulp. $6^{\text {th }}$ ed. St. Louis; CV Mosby: 1998. p. 219-71.

2. European Society of Endodontology. Quality guidelines for endodontic treatment: consensus report of the European Society of Endodontology. Int Endod J 2006;39:921-30.

3. Chandra BS, Gopıkrıshna V. Obturation of Radicular Space. Grossmans Endodontic Practice. $12^{\text {th }}$ ed. New Delhi; Wolters kluwer: 2013. p. 278-300. 
4. Petersson K, Petersson A, Olsson B, Hakansson J, Wennberg A. Technical quality of root fillings in an adult Swedish population. Endod Dent Traumatol 1986;2:99-102.

5. De Moor RJ, Hommez GM, De Boever JG, Delme KI, Martens GE. Periapical health related to the quality of root canal treatment in a Belgian population. Int Endod J 2000;33:113-20.

6. Boltacz-Rzepkowska E, Pawlicka H. Radiographic features and outcome of root canal treatment carried out in the Lodz region of Poland. Int Endod J 2003;36:27-32.

7. İlgüy $D$, İlgüy $M$, Fişekçioğlu E, Ersan N, Tanalp J, Dölekoğlu S. Assessment of root canal treatment outcomes performed by turkish dental students: results after two years. J Dent Ed 2013;77:502-50.

8. Kabak Y, Abbott PV. Prevalence of apical periodontitis and the quality of endodontic treatment in an adult Belarusian population. Int Endod J 2005;38:238-45.

9. Burke FM, Lynch $C D$, Ní Ríordáin R, Hannigan A. Technical quality of root canal fillings performed in a dental school and the associated retention of root-filled teeth: a clinical follow-up study over a 5year period. J Oral Rehabil 2009;36:508-15.

10. Bhatt M, Coil J, Chehroudi B, Esteves A, Aleksejuniene J, MacDonald D. Clinical decisionmaking and importance of the $A A E / A A O M R$ position statement for CBCT examination in endodontic cases. Int End J 2021;54:26-37.

11. MacDonald D. Cone-beam computed tomography. In: D MacDonald, ed. Oral and Maxillofacial radiology: A Diagnostic Approach, $2^{\text {nd }}$ ed. New jersey: Wiley Blackwell: 2020. p. 97- 100.

12. Hommez GM, Coppens CR, De Moor RJ. Periapical health related to the quality of coronal restorations and root fillings. Int Endod J 2002;35:680-9.

13. Buckley M, Spangberg LSW. The prevalence and technical quality of endodontic treatment in an American subpopulation. Oral Surg Oral Med Oral Pathol Oral Radiol Endod 1995;79:92-100.

14. Mothanna K. AlRahabi. Technical quality assessment of root canal treatment performed by preclinical dental students at Taibah University. KSA J Taibah Univ Med Sci 2017; 12:27-33.

15. Bradford R, Johnson BR, Fayad MI, Witherspoon DE. Periradicular Surgery. In: Hargreaves KM, Cohen S, Berman LH eds. Cohen's pathways of the pulp. $10^{\text {th }}$ ed. St. Louis; Mosby Elsevier: 2011. p. 720-76.
16. Dugas NN, Lawrence HP, Jeplitsky PE, Pharoah MJ. Periapical health and treatment quality assessment of root-filled teeth in two Canadian populations. Int Endod J 2003;36: 181-92.

17. Haznedaroğlu F, Dulger J, Ersev H, Dişci R, Şirin Ş. Endodonlik tedavilerde başarı oranının istatistiksel olarak değerlendirilmesi. Dişhek Derg 1995;4:3641.

18. Dammaschke T, Steven D, Kaup M, Ott KH. Longterm survival of root-canal-treated teeth: a retrospective study over 10 years. J Endodon 2003;29:638-43.

19. Ceyhanlı KT, Çelik D, Çıkman A, Taşdemir T. Stajyer diş hekimleri tarafından yapılan kök kanal dolgularının teknik kalitesinin radyografik olarak değerlendirilmesi. EÜ Dişhek Fak Derg 2015;36:2531.

20. Yoldaş O, Oztunc $H$, Topuz A, İşci AŞ. 4. Sınıf ve 5 . Sınıf dişhekimliği öğrencileri tarafından yapılan kanal tedavilerinin kalitesinin radyolojik değerlendirilmesi. Ondokuz Mayis Univ Dis Hek Fak Deıg 2004;5:65-68.

21. Lynch CD, Burke FM. Quality of root canal fillings performed by undergraduate dental students on single-rooted teeth. Eur J Dent Ed 2006;10:67-72.

22. Gound TG, Sather JP, Kong TS, Makkawy HA, Marx DB. Graduating dental students' ability to produce quality root canal fillings using single or multiple cone obturation techniques. J Dent Educ 2009; 73:696-705.

23. Çelik D., Taşdemir T., Er K. Comparative study of 6 rotary nickel-titanium systems and hand instrumentation for root canal preparation in severely curved root canals of extracted teeth. J Endod 2013;2:278-82.

24. Nakagawa R, Alves J, Buono V, Bahia M. Flexibility and torsional behaviour of rotary nickel-titanium PathFile, RaCe ISO 10, Scout RaCe and stainless steel K-File hand instruments. Int Endod ] 2014:290-7.

25. Cheung GS, Liu CS. A retrospective study of endodontic treatment outcome between nickeltitanium rotary and stainless steel hand filing techniques. J Endod 2009;35: 938-43.

26. Garip G, Nur BG, Altunsoy M, Ok E. Süt dişlerinde nikel titanyum döner aletlerinin kullanımının değerlendirilmesi. Atatürk Üniv Diş Hek Fak Derg 2016; 25.

27. Gökyay S, Çalışkan E. Endodontic systems working with reciprocal movements for Instrumentation of root canals. Aydın Dental 2015; 1: 51-60. 
28. Adıgüzel $M$, Tüfekçi $P$. Waveone, recıproc ve twısted fıle adaptıve döner sistem eğelerin çift kurvatürlü (s-şekilli) kanallarda döngüsel yorulma dirençlerinin karşılaştırılması. Atatürk Üniv Diş Hek Fak Derg 2018; 28: 199-203.

29. Koçak MM, Koçak S, Türker SA, Sağlam BC. Cleaning efficacy of reciprocal and rotary systems in the removal of root canal filling material. J Conserv Dent 2016;19:184-8.

30. Çapar İD, Ertas H, Gök T. Farklı dolum teknikleri ile doldurulan kök kanallarından kanal dolgu malzemesinin uzaklaştırılmasının değerlendirilmesi. SDÜ Sağlık Bil Derg 2014; 5: 51-5.

31. Ruddle $\mathrm{CJ}$. Cleaning and shaping the root canal system, in Pathway of the pulp, S.Cohen, RC Burns. $8^{\text {th }}$ ed. St. Louis; CV Mosby: 2002. p. 241-5.

32. El Ayouti A, Chu AL, Kimionis I, Klein C, Weiger R, Löst C. Efficacy of rotary instruments with greater taper in preparing oval root canals. Int Endod J 2008;41:1088-92.

33. Zogheib C, Hanna M, Pasqualini D, Naaman A. Quantitative volumetric analysis of cross-linked gutta-percha obturators. Ann Stomatol 2016;7:4651.

34. Ozkocak I, Sonat B. Evaluation of effects on the adhesion of various root canal sealers after Er:YAG Laser and irrigants are used on the dentin surface. J Endod 2015;41: 1331-6.

35. Naito T. Better success rate for root canal therapy when treatment includes obturation short of the apex. Evid Based Dent 2005;6:45.

\author{
Sorumlu Yazarın Yazışma Adresi \\ Dr. M.Emre SÖNMEZATEŞ \\ Karaağaç Konarlı Mah. Ortayol Cad. \\ No:199 Arsuz/Hatay \\ e-mail: emre_sonmezates@hotmail.com
}

